\title{
DNA methylome and transcriptome analysis established a model of four differentially methylated positions (DMPs) as a diagnostic marker in esophageal adenocarcinoma early detection
}

\author{
Weilin Peng ${ }^{1,2}$, Guangxu Tu ${ }^{1,2}$, Zhenyu Zhao ${ }^{1,2}$, Boxue He ${ }^{1,2}$, Qidong Cai ${ }^{1,2}$, Pengfei Zhang ${ }^{1,2}$, Xiong Peng ${ }^{1,2}$, \\ Shuai Shi ${ }^{1,2}$, Xiang Wang ${ }^{\text {Corresp. 1,2 }}$ \\ 1 Hunan Key Laboratory of Early Diagnosis and Precise Treatment of Lung Cancer, The Second Xiangya Hospital of Central South University, Central South \\ University, Changsha, Hunan, China \\ 2 Department of Thoracic Surgery, The Second Xiangya Hospital of Central South University, Central South University, Changsha, Hunan, China \\ Corresponding Author: Xiang Wang \\ Email address: wangxiang@csu.edu.cn
}

Background: Esophageal carcinogenesis involves in alterations of DNA methylation and gene transcription. This study profiled genomic DNA methylome vs. gene expression using transcriptome data on esophageal adenocarcinoma (EAC) tissues from the online databases in order to identify methylation biomarkers in EAC early diagnosis.

Materials and Methods: The DNA methylome and transcriptome data were downloaded from the UCSC Xena, Gene Expression Omnibus (GEO), and The Cancer Genome Atlas (TCGA) databases and then bioinformatically analyzed for the differentially methylated positions (DMPs) vs. gene expression between EAC and normal tissues. The highly methylated DMPs vs. reduced gene expression in EAC were selected and then stratified with those of the corresponding normal blood samples and other common human cancers to construct an EAC-specific diagnostic model. The usefulness of this model was further verified in other three GEO datasets of EAC tissues.

Result: A total of 841 DMPs were associated with expression of 320 genes, some of which were aberrantly methylated in EAC tissues. Further analysis showed that four (cg07589773, cg10474350, cg13011388, and cg15208375 mapped to gene IKZF1, HOXA7, EFS and TSHZ3, respectively) of these 841 DMPs could form and establish a diagnostic model after stratified them with the corresponding normal blood samples and other common human cancers. The data were further validated in other three GEO datasets on EAC tissues in early EAC diagnosis.

Conclusion: This study revealed a diagnostic model of four genes methylation to diagnose EAC early. Further study will confirm the usefulness of this model in a prospective EAC cases. 


\section{DNA methylome and transcriptome analysis established a model of}

2 four differentially methylated positions (DMPs) as a diagnostic

\section{3 marker in esophageal adenocarcinoma early detection}

4

5 Weilin Peng ${ }^{1,2}$, Guangxu Tu ${ }^{1,2}$, Zhenyu Zhao ${ }^{1,2}$, Boxue He ${ }^{1,2}$, Qidong Cai1 ${ }^{1,2}$, Pengfei Zhang ${ }^{1,2}$,

6 Xiong Peng ${ }^{1,2}$, Shuai Shi ${ }^{1,2}$, Xiang Wang ${ }^{1,2}$

8 'Department of Thoracic Surgery, The Second Xiangya Hospital of Central South University,

9410011 Changsha, Hunan, China

$10 \quad{ }^{2}$ Hunan Key Laboratory of Early Diagnosis and Precise Treatment of Lung Cancer, The Second

11 Xiangya Hospital of Central South University, 410011 Changsha, Hunan, China

13 Corresponding Author:

14 Xiang Wang, M.D., at the Department of Thoracic Surgery, The Second Xiangya Hospital of

15 Central South University, 139 Renmin Road, Changsha, Hunan 410011, China; Tel.: +86

16 15874978585; Email: wangxiang@csu.edu.cn

17

18 


\section{Abstract}

20 Background: Esophageal carcinogenesis involves in alterations of DNA methylation and gene

21 transcription. This study profiled genomic DNA methylome vs. gene expression using

22 transcriptome data on esophageal adenocarcinoma (EAC) tissues from the online databases in

23 order to identify methylation biomarkers in EAC early diagnosis.

24 Materials and Methods: The DNA methylome and transcriptome data were downloaded from

25 the UCSC Xena, Gene Expression Omnibus (GEO), and The Cancer Genome Atlas (TCGA)

26 databases and then bioinformatically analyzed for the differentially methylated positions (DMPs)

27 vs. gene expression between EAC and normal tissues. The highly methylated DMPs vs. reduced

28 gene expression in EAC were selected and then stratified with those of the corresponding normal

29 blood samples and other common human cancers to construct an EAC-specific diagnostic model.

30 The usefulness of this model was further verified in other three GEO datasets of EAC tissues.

31 Result: A total of 841 DMPs were associated with expression of 320 genes, some of which were

32 aberrantly methylated in EAC tissues. Further analysis showed that four (cg07589773,

33 cg10474350, cg13011388, and cg15208375 mapped to gene IKZF1, HOXA7, EFS and TSHZ3,

34 respectively) of these 841 DMPs could form and establish a diagnostic model after stratified

35 them with the corresponding normal blood samples and other common human cancers. The data

36 were further validated in other three GEO datasets on EAC tissues in early EAC diagnosis.

37 Conclusion: This study revealed a diagnostic model of four genes methylation to diagnose EAC

38 early. Further study will confirm the usefulness of this model in a prospective EAC cases.

39 Keywords: Esophageal adenocarcinoma, DNA methylation, diagnostic biomarkers, TCGA 
41

42 Esophageal cancer (EC) is one of the most commonly diagnosed digestive tract carcinomas, 43

ranking as the ninth global cancer burden among all human cancers (Global Burden of Disease Cancer et al. 2015). Histologically, EC can be mainly classified into esophageal squamous cell carcinoma (ESCC) and esophageal adenocarcinoma (EAC), which have distinct epidemiological and pathological characteristics (Lagergren et al. 2017; Xu 2009) and different molecular profiles and risk factors (Lagergren et al. 2017). For example, ESCC incidence is declined recently, whereas EAC incidence has been increasing in the past decades (Cook et al. 2009; Edgren et al. 2013; Lin et al. 2013). In treatment of early staged EC, specifically when tumor lesion is limited in the mucosa with no metastasis, either endoscopic mucosal resection (EMR) or dissection together with radiofrequency ablation is the first-line therapy of choice, instead of more aggressive esophagectomy, because such treatment selection is safer, less tissue damages, and largely improved the quality of life for patients as well as better long-term outcomes than those of esophagectomy (Fitzgerald et al. 2014; Lordick et al. 2016; Pech et al. 2014). However, such early staged EC were rarely caught clinically; thus, search for and identification of novel biomarkers could lead to more diagnosis of the early staged ECs. To date, the gold standard in EC diagnosis is endoscopy, but it requires more expense and expertise, and may cause damage to patients (Smyth et al. 2017). In this regard, development and evaluation of novel, safer, economic, and effective alternatives in diagnosis of early esophageal cancers are of great clinical significance (Lagergren et al. 2017; Xu 2009).

Towards this end, assessment of epigenetic alterations in various human cancers showed a great potential as biomarkers in cancer early diagnosis; for example, detection of aberrant DNA methylation, one of the major forms in epigenetic alterations, had also been observed to associate with development of numerous human diseases, including cancer (Robertson 2005). Altered DNA methylation showed as an early step in transformation of metaplasia to dysplasia and neoplasia (Alvarez et al. 2011b; Kaz et al. 2011; Smith et al. 2008; Xu et al. 2013b). DNA 
67 methylation, a process in transferring a methyl group onto the C5 position of the cytosine, can 68 negatively regulate gene expression in general; however, aberrantly hypermethylation of tumor

69 70 suppressor genes could silence expression of these genes and promotes or contributes to cancer development (Hao et al. 2017). For example, methylation of Ras association domain-containing protein 1A (RASSF1A) occurred in ovarian cancer ( $\mathrm{Si}$ et al. 2014) and esophageal cancer (Guo et al. 2016; Yang et al. 2014). Moreover, alterations of DNA methylation (Laird 2003) and tumorspecific DNA methylation profiles could be detected repeatedly in early stage of cancers (Koch et al. 2018). In ESCC, aberrantly methylated genes were significantly enriched in IL-10 antiinflammatory signaling and cell communication pathway (Lima et al. 2011). Different from ESCC, several cancer-associated pathway genes were aberrantly methylated in EAC, including genes in the epithelial-mesenchymal transition (EMT), cell adhesion, Wingless and Int-1 (WNT), and Transforming growth factor (TGF) pathways (Kaz et al. 2011; Xu et al. 2013a). However, to date, most of these DNA methylome studies of EAC were restricted to handful CpG island sites of selected genes, like the Illumine Human Methylation 27K array (Alvarez et al. 2011a; Kaz et al. 2011; Smith et al. 2008; Xu et al. 2013a).

In this study, we conducted a systematically investigation into EAC genome-wide methylome and transcriptome profiles to identify genome-wide differentially hypermethylated CpG loci using the online The Cancer Genome Atlas (TCGA) and the Gene Expression Omnibus (GEO) databases. Afterwards, we identified different DNA methylation sites in EAC tissues vs. those of normal esophagus tissues and then selected those with reduced expression of the corresponding genes, leading to four hypermethylation sites by using the least absolute shrinkage and selection operator (LASSO) regression analysis and to establishing a model of these four sites as a diagnostic model using the logistic regression analysis. We then verified this model in other three independent datasets (GSE81334, GSE89181, and GSE104707). We expected to provide a useful model in help in early EAC diagnosis. 
93 MATERIALS AND METHODS

\section{$94 \quad 2.1$ Database search and data download and initial analysis}

95 We first performed database search and downloaded data from UCSC Xena, TCGA, and GEO

96 databases, respectively. Our detailed data process and analysis procedures are listed in Figure 1.

97 In brief, DNA methylation data on EAC and normal squamous esophagus were collected from

98 the UCSC Xena database (https://xenabrowser.net/) (Goldman et al. 2015). The database

99 includes DNA methylation data in different human cancers, while there were two counts in a

100 given $\mathrm{CpG}$ island, i.e., a methylated intensity (M) and an unmethylated intensity (U) and the

101 methylation levels $(\beta)$ were summarized as $\mathrm{M} /(\mathrm{M}+\mathrm{U}+100)$. Clinicopathological data and RNA-

102 Seq data on gene expression in EAC were downloaded from TCGA

103 (https://portal.gdc.cancer.gov/). The DNA methylation data on other human cancers were also

104 extracted from the UCSC Xena database, including ACC_T, Adrenocortical carcinoma;

105 BLCA_T, Bladder Urothelial carcinoma; BRCA_T, Breast invasive carcinoma; CESC_T,

106 Cervical squamous cell carcinoma and endocervical adenocarcinoma; CHOL_T,

107 Cholangiocarcinoma; COAD_T, Colon adenocarcinoma; DLBC_T, Diffuse Large B-cell

108 Lymphoma; GBM_T, Glioblastoma multiforme; HNSC_T, Head and Neck squamous cell

109 carcinoma; KICH_T, Kidney Chromophobe; KIRC_T, Kidney renal clear cell carcinoma;

110 KIRP_T, Kidney renal papillary cell carcinoma; LAML_T, Acute Myeloid Leukemia; LGG_T,

111 Brain Lower Grade Glioma; LIHC_T, Liver hepatocellular carcinoma; LUAD_T, Lung

112 adenocarcinoma; LUSC_T, Lung squamous cell carcinoma; MESO_T, Mesothlioma, OV_T,

113 Ovarian serous cystadenocarcinoma; PAAD_T, Pancreatic adenocarcinoma; PCPG_T,

114 Pheochromocytoma and Paraganglioma; PRAD_T, Prostate adenocarcinoma; READ_T, Rectum

115 adenocarcinoma; STAD_T, stomach adenocarcinoma; UCEC_T, Uterine Corpus Endometrial

116 Carcinoma. In addition, we also downloaded five independent DNA methylation datasets on

117 EAC and normal squamous esophagus from the GEO database, including GSE72872 (Krause et

118 al. 2016), GSE69270 (Kananen et al. 2016; Mishra et al. 2020), GSE81334, GSE89181 (Kaz et 
119 al. 2016), and GSE104707 (Luebeck et al. 2017). These data were then processed by using the

120 Illumina 450K array, analyzed, and annotated by the ChAMP R software package (Tian et al.

121 2017). However, the samples without tumor stage information were removed, the CpG

122 methylation data missing in more than $10 \%$ of samples were also filtered out, and data using the

123 probes being localized in allosome, non-CpG probes or single-nucleotide polymorphism-related

124 probes, or multi-hit probes were further removed by the champ.filter function of the ChAMP R

125 package. After that, the rest real $\mathrm{CpG}$ probes with no methylation values were processed using

126 the R impute.knn function. In addition, the RNA-Seq data on gene expression in EAC tissues

127 were acquired from TCGA dataset, and subsequently analyzed for differentially expressed genes

128 vs. the normal esophageal tissues using DESeq R package.

129

$130 \quad 2.2$ Analysis of differential DNA methylation CpGs vs. differentially expressed genes

131 To identify the differentially methylated positions (DMPs) involved in the early EAC

132 tumorigenesis, we assigned TCGA EAC tumor data into two subtypes stratified by stage I/II vs.

133 III/IV. Since gene transcription was significantly influenced by level of the CpG island

134 methylation in their gene promoter regions, the $\mathrm{CpG}$ sites localized at the $200 \mathrm{bp}$ upstream of the

135 transcription start site (TSS200) and/or TSS1500 were selected for further analysis. Significant

136 DMPs were identified by using the functional champ.DMP in the ChAMP R package, while the

137 criterion of DMPs was set with the false discovery rate (FDR) less than 0.05 , while the absolute

138 difference in $\beta$ value exceeded 0.2 . Thus, the $\mathrm{CpG}$ sites met this criterion were considered as

139 significant DMPs. After that, we selected the intersectional DMPs on TCGA EAC and

140 GEO72872 datasets as candidate DMPs.

141

142 2.3 Data correlational analysis and construction of a candidate diagnostic DNA

143 methylation model

144 We performed Spearman correlation test and selected DMPs, whose level were significantly 
145 negatively associated with gene expression using a $P$ value less than 0.05 and coefficient less

146 than -0.4. We then identified and selected candidate DMPs as a diagnostic model, i.e., we first

147 searched the differentially methylated CpGs by analyzed them for three times, i.e. TCGA stage

148 I/II EAC samples vs. the normal squamous esophagus samples, TCGA stage III/IV EAC samples

149 vs. normal squamous esophagus samples, and GSE72872EAC samples vs. the normal squamous

150 esophagus samples. We identified a total of 4852 hypermethylated $\mathrm{CpG}$ sites in all three

151 comparisons and then associated them with expression of their corresponding genes and found

152841 hypermethylated $\mathrm{CpG}$ sites to negatively associate with gene expression. Furthermore, we

153 stratified these 841 DMPs with that of normal blood samples of GSE69270 dataset to exclude

154 seven of them based on a higher average $\beta$ value than that of EAC samples, leading to the

155 remaining 834 DMPs. After analyzed them against the ESCC samples, we obtained 257 DMPs

156 with a mean methylation level less than 0.1 in ESCC samples and then utilized dichotomous

157 logistic regression analysis and LASSO methods to obtain four DMPs as a model to diagnose

158 EAC early.

159

160

\subsection{Validation of the diagnostic model of the four DMPs in EAC}

161 After that, we verified the usefulness of this model in EAC diagnosis based on the $\beta$ value and

162 risk score between 24 EAC samples and 11 normal squamous esophagus samples in GSE89181

163 dataset. We then constructed the receiver operating characteristics (ROC) using the pROC R

164 package according to a previous study (Robin et al. 2011) and obtained the area under the curve

165 (AUC) value for the specificity and sensitivity. Afterwards, we performed the same analysis for

166 the GSE72872, GSE81334, and GSE104707 data. And usefulness of this model in early staged

167 EAC diagnosis was also verified in stage I EAC cancers of TCGA and GSE89181 by using the

168 same method.

169

$170 \quad 2.5$ Statistical analysis

Peer) reviewing PDF | (2020:12:56122:1:1:NEW 16 Mar 2021) 
171 We performed Shapiro-Wilk test to normalize the downloaded data and Wilcoxon rank-sum test

172 to compare methylation levels and the risk scores in different data groups, e.g., EAC vs. normal

173 tissues. We also conducted the Spearman correlation test to correlate methylation levels and gene

174 expression. All statistical analyses were performed by using the R 3.6.2 (www.r-project.org) or

175 GraphPad Prism 8.2.1 (GraphPad Software, La Jolla, CA, USA). A p value that was equal to or

176 less than 0.05 was considered as statistically significant.

177

\section{RESULTS}

179 3.1 Identification of DMPs in EAC

180 We first analyzed DMPs using data on 89 EAC and 16 normal squamous esophagus samples

181 from the UCSC Xena dataset, while EAC samples without TNM information were excluded,

182 leading to 34 stage I/II and 34 stage III/IV samples. We found a total of $95248 \mathrm{CpG}$ sites

183 localized at the $200 \mathrm{bp}$ upstream of the transcription start site (TSS200) or TSS1500 and 9072

184 DMPs between stage I/II EAC and normal samples (Fig. 2A) and 8338 DMPs between stage

185 III/IV EAC and normal esophagus tissues (Fig. 2B). Similarly, we found 9855 DMPs out of

18691602 methylated $\mathrm{CpG}$ sites in 125 EAC and 64 normal samples from GSE72872 dataset (Fig.

187 2C). Ultimately, we identified a total of 5392 DMPS (4852 hypermethylated and 540

188 hypomethylated DMPs) coinciding in all three cohorts (Fig. 2D-E). We then performed the GO

189 and KEGG pathway analyses of the corresponding 1796 genes and the data are shown in

190 supplemental Fig. 1, i.e., these genes were significantly enriched in cell growth, EMT, PI3K-Akt

191 signaling and Wnt signaling pathway, respectively. These DMPs localized in the different

192 chromosomes (Fig. 3A) and the quantity of these DMPs showed that they were more

193 concentrated in chromosome 1 and 2 with 384 and 409 DMPs, respectively, whereas

194 chromosome 21 and 22 had least DMPs with 58 and 52, respectively. The majority of these

195 DMPs were hypermethylated (90\%), although their distribution had no distinct difference in

196 TSS200 or TSS1500 (Fig. 3B). The number of the hypermethylated DMPs was reduced 
197 dramatically in "opensea", "shelves" and "shores" regions (Fig. 3C).

198

\subsection{Association of DMPs with expression of the corresponding genes}

200 Of these 5392 DMPs coinciding in all three cohorts of EAC samples, the 4527 hypermethylated

201 DMPs were corresponding to 1262 genes and 475 hypomethylated DMPs to 374 genes.

202

Moreover, 841 hypermethylated DMPs was reversely associated expression of 320 genes and 57

hypomethylated DMPs were negatively associated with expression of 43 genes based on

204 Spearman correlation analysis of methylome and transcriptome data. The heatmap of these 898

205 DMPs is illustrated in Fig. 4A, while the heatmap of the corresponding genes is shown in Fig. 4B,

206 suggesting that there was a distinct difference in methylation level and gene expression between

207 EAC and normal samples.

208

209 3.3 Establishment of DMPs as a diagnostic model in EAC

210 After that, we screened hypermethylated DMPs between EAC and normal samples and excluded

211 those with higher methylation levels in normal blood samples than in EAC tissues. We found a

212 total of 834 hypermethylated DMPs, among which 649 CpGs also occurred in all six datasets,

213 and heatmap of these 649 CpGs is shown in Fig. 5A. Our unsupervised hierarchical clustering

214 analysis revealed that EAC samples had distinct difference in DMPS levels vs. those of normal

215 blood or normal esophagus samples. Furthermore, we excluded 577 from 834 DMPs based on

216 the mean $\beta$ value greater than 0.1 in ESSC samples, leading to 257 DMPs to be able to diagnose

217 EAC. We then performed the binary logistic regression and LASSO methods and identified four

218 CpGs to construct the risk score model (Table 1), in which we utilized the formula: The risk

219 score $=2.186 \times \beta$ value of $\operatorname{cg} 07589773+0.504 \times \beta$ value of $\operatorname{cg} 10474350+1.550 \times \beta$ value of

$220 \operatorname{cg} 13011388+2.371 \times \beta$ value of $\operatorname{cg} 15208375$. The risk score of different EAC datasets was

221 significantly higher than that of the ESSC dataset (Fig. 5B), while the methylation levels of these

222 four CpGs were compared in all other cancer types from the UCSC Xena database (Fig. 5C). 
223 These results showed that these four CpGs were the robust candidate EAC-specific diagnostic

224 biomarkers. These four CpGs were mapped to four different genes (IKZF1, HOXA7, EFS, and

225 TSHZ3), and our Kaplan Meier curves of these four genes showed that their expression level did

226 not affect prognosis of EAC patients (Supplemental Fig. 2). The process of the CpG methylation

227 was regulated by many factors, some of which had been identified, including DNA

228 methyltransferase, DNA demethylase, histone methyltransferase, and histone demethylase. The

229 correlation between these regulators and these four genes were investigated, results of which

230 showed that IKZF1 was significantly associated with SETBP1 level and inversely associated

231 with levels of SUV39H1, SET, SMYD5, SUV39H2, DPY30 and WDR5; EFS significantly

232 associated with PRDM2, SETBP1 and TET2 but inversely associated with DNMT1; TSHZ3

233 significantly associated with SETBP1 and inversely associated with SUV39H1, SET, SMYD5,

234 SUV39H2, IDH2, and WDR5 (Supplemental Fig. 3).

235

236 3.4 Validation of this four DMPS as a signature to diagnose EAC

237 After that, we verified the usefulness of this model of four DMPs as diagnostic markers for EAC.

238 Fig. 6A-D illustrated that there was significant higher methylation levels of four DMPs between

239 tumor and normal samples in external datasets. Since methylation in adjacent sites had similar

240 pattern (Bibikova et al. 2011), methylation levels of other CpG sites in TSS200 and/or TSS1500

241 of four genes mapped to these four $\mathrm{CpGs}$ were examined, result showed all other $\mathrm{CpG}$ sites were

242 hypermethylated in EAC tissues vs. that of normal esophagus tissues in TCGA EAC dataset (Fig.

243 7A-D), consistent with the four CpGs. The risk scores calculated based on the model also

244 showed significant difference between EAC and normal samples (Fig. 8A-D and Supplemental

245 Fig. 4A). The AUC values of this model in TCGA, GSE72872, GSE81334, GSE89181, and

246 GSE104707 datasets were 0.9, 0.95, 0.989, 0.992, and 0.998, respectively (Fig. 9A-D and

247 Supplemental Fig. 4B). The sensitivity and specificity of this model in EAC diagnosis were

2480.978 and $0.875,0.88$ and $0.953,1$ and $0.893,0.917$ and 1,1 and 0.962 , respectively in TCGA, 

usefulness of this model of the four methylation biomarkers in diagnosis of early EAC. We first assessed the methylation levels of the four CpGs between stage I EAC and normal tissues in GSE89181 and the result showed all four CpGs were hypermethylated in stage I EAC vs. normal esophagus (Supplemental Fig. 5). The risk score of the stage I EAC vs. the normal tissues in TCGA and GSE89181 datasets was also distinctly different (Fig. 10A, C). The ROC curves were plotted for TCGA and GSE89181 stage I EAC (Fig. 10B, D). In TCGA dataset the AUC value was 0.903 and the sensitivity and specificity were 1 and 0.812 , respectively. The AUC value and the sensitivity and specificity were all 1 in GSE89181 dataset.

\section{DISCUSSION}

260 In the current study, we first profiled global DNA methylations on EAC identified by using the Illumina Human Methylation 450K BeadChips and then compared the data with gene expression data on RNA-Seq datasets. We identified differential methylated CpGs and stratified by their gene expression and found a total of 841 hypermethylated DMPs with downregulated genes. After that, we further stratified these 841 DMPs with those of ESCC and normal blood samples, and performed binary logistic regression and LASSO analyses to obtain four of them as a model in early diagnosis of EAC. These four DMPs corresponding to four different protein-coding genes, i.e., Ikaros family zinc finger protein 1 (IKZF1), Homeobox protein Hox-A7 (HOXA7), Embryonal fyn-associated substrate (EFS), and Teashirt homolog 3 (TSHZ3). We then validated this model of the four methylation biomarkers in other three independent GEO datasets. Our model also showed very high values of the AUC and high sensitivity and specificity in early

271 EAC diagnosis. Indeed, the characteristics of a clinical applicable diagnostic biomarker should

272 include high sensitivity and specificity in diagnosis of early stage cancer, but not mistakenly

273 diagnose other cancer types or non-cancerous diseases, in addition to non-invasive and relatively 274 economic procedure. In the present study, we established this model of four CpGs for EAC 
275 diagnosis, indicating a great potential biomarker in early EAC detection, although this model

276 was not validated in the blood or other non-invasive biospecimens. Future study will evaluate it

277 in serum samples to verify the usefulness.

278 DNA methylation epigenetically modifies gene expression; thus, aberrant gene promoter

279 methylation was associated with cancer development and progression(Robertson 2005). The

280 current study profiled global DNA methylations on EAC and identified a large set of genomic

281 DNA methylations on EAC, some of which were shown in previous studies. For example, the E3

282 ubiquitin-protein ligase CHFR showed to be required in maintenance of the antephase

283 checkpoint that regulates cell cycle and was hypermethylated in EAC (Soutto et al. 2010). The

284 promoters of glutathione peroxidase 7 (GPX7) and glutathione S-transferase Mu 2 (GSTM2)

285 were reported to be frequently hypermethylated in $67 \%$ and $69 \%$ of EAC, respectively,

286 expression of which was also reduced respectively (Peng et al. 2009). Moreover, aberrant

287 hypermethylation of the secreted frizzled-related protein 1 ( $S F R P 1)$ promoter regions associated

288 with reduced SFRP1 expression, which occurred in early EAC (Zou et al. 2005a), while altered

289 methylation in Eyes absent homolog 4 (EYA4) promoter occurred in esophageal mucosa

290 metaplasia and Barrett's esophagus progression to EAC (Zou et al. 2005b) and hypermethylation

291 of Runt-related transcription factor 3 (RUNX3) promoter was reported as an independent risk

292 factor associated with Barrett's esophagus-related EAC development (Schulmann et al. 2005).

293 However, detection and analysis of this large amount of gene methylations as biomarker are not

294 practical. Thus, for EAC-specific biomarker development, we further stratified our DNA

295 methylation data using those of normal blood samples and performed LASSO analyses to narrow

296 down to four DMPs, which greatly reduced the numbers of gene methylations and also validated

297 them in other three independent EAC samples and stage I EAC samples. We can therefore

298 confidently suggest that this model of the four DNA methylation markers could be useful in

299 early EAC detection.

300 As we know, IKZF1, a transcription factor, is a known regulator of immune cells 
301 development, mainly in early B cells, CD4+ T cells, altered IKZF1expression has been linked to

302 the development of chronic lymphocytic leukemia (Kastner \& Chan 2011; Oliveira et al. 2019),

303 while HOXA7 is a DNA-binding transcription factor to regulate gene expression, morphogenesis,

304 and differentiation ( $\mathrm{Li}$ et al. 2020) and showed upregulated expression in ESCC (Chen et al.

305 2005) and laryngeal squamous cell cancer (Li et al. 2020), whereas it was downregulated

306 expression in renal clear cell carcinoma (Cui et al. 2020). Moreover, EFS protein acts as a

307 scaffolding protein for cell signaling in the immune system and altered EFS expression was

308 associated with cancer development (Neumann et al. 2011; Sertkaya et al. 2015; Vital et al.

309 2010). In addition, TSHZ3 controls breathing and has been identified as a critical region of the

310 heterozygous deletions at 19q12-q13.11, in development of autism spectrum disorder symptoms

311 (Caubit et al. 2016). TSHZ3 expression, as one of five genes, was high in tongue SCC (Zeng et

312 al. 2019) and TSHZ3 was duplicated in ovarian and triple negative breast cancers (McBride et al.

313 2012), while TSHZ3, as one of ten genes, inhibited the p53 activity in multiple non-small cell

314 lung cancer cell lines (Siebring-van Olst et al. 2017). However, to date, there are no reports of

315 aberrant expression or activities of these four genes in EAC. The role of these four genes in EAC

316 needs more study.

317 However, it is the limitation of this study, a technique that can sensitively detect methylation

318 conditions of the circulating tumor DNAs will be more useful; thus, we will investigate whether

319 this model of the four gene methylations can use blood samples. Although these four methylation

320 sites in EAC had relatively higher $\beta$ values than those in other cancer types, indicating that this

321 model could not effectively distinguish EAC from other cancer types. So identification of more

322 specific methylation sites will be warranted in our future work. Moreover, another limitation of

323 this study was that we didn't further assess the role of these four genes in control of esophageal

324 tumorigenesis.

325

326 Conclusion 
327 The current data demonstrated that detection of aberrant DNA methylation in four CpG sites as a

328 model could sensitively and specifically diagnose EAC early in four different online EAC

329 datasets. Further study will validate and investigate the mechanisms underlying aberrant

330 methylation in EAC tumorigenesis. Future study will also validate this promising diagnostic

331 model of four biomarkers in prospective clinical EAC samples.

332

\section{Acknowledgements}

334 The authors would like to thank Professor Yongguang Tao for his instruction throughout the

335 designing and writing process. It is with regret that not all relevant studies could be cited due to 336 space limitations.

337

\section{References}

339

340

341

342

343

344

345

346

347

348

349

350

351

352

353

354

355

356

Alvarez H, Opalinska J, Zhou L, Sohal D, Fazzari M, Yu Y, Montagna C, Montgomery E, Canto M, Dunbar K, Wang J, Roa J, Mo Y, Bhagat T, Ramesh K, Cannizzaro L, Mollenhauer J, Thompson R, Suzuki M, Meltzer S, Meltzer S, Melnick A, Greally J, Maitra A, and Verma A. 2011a. Widespread hypomethylation occurs early and synergizes with gene amplification during esophageal carcinogenesis. PLoS genetics 7:e1001356. 10.1371/journal.pgen.1001356

Alvarez H, Opalinska J, Zhou L, Sohal D, Fazzari MJ, Yu Y, Montagna C, Montgomery EA, Canto M, Dunbar KB, Wang J, Roa JC, Mo Y, Bhagat T, Ramesh KH, Cannizzaro L, Mollenhauer J, Thompson RF, Suzuki M, Meltzer SJ, Melnick A, Greally JM, Maitra A, and Verma A. 2011b. Widespread hypomethylation occurs early and synergizes with gene amplification during esophageal carcinogenesis. PLoS Genet 7:e1001356. 10.1371/journal.pgen.1001356

Bibikova M, Barnes B, Tsan C, Ho V, Klotzle B, Le JM, Delano D, Zhang L, Schroth GP, Gunderson KL, Fan JB, and Shen R. 2011. High density DNA methylation array with single CpG site resolution. Genomics 98:288295. 10.1016/j.ygeno.2011.07.007

Caubit X, Gubellini P, Andrieux J, Roubertoux PL, Metwaly M, Jacq B, Fatmi A, Had-Aissouni L, Kwan KY, Salin P, Carlier M, Liedén A, Rudd E, Shinawi M, Vincent-Delorme C, Cuisset JM, Lemaitre MP, Abderrehamane F, Duban B, Lemaitre JF, Woolf AS, Bockenhauer D, Severac D, Dubois E, Zhu Y, Sestan N, Garratt AN, Lydia Kerkerian-Le G, and Fasano L. 2016. TSHZ3 deletion causes an autism syndrome and defects in cortical projection neurons. Nat Genet 48:1359-1369. 10.1038/ng.3681 
357

358

359

360

361

362

363

364

365

366

367

368

369

370

371

372

373

374

375

376

377

378

379

380

381

382

383

384

385

386

387

388

389

390

Chen KN, Gu ZD, Ke Y, Li JY, Shi XT, and Xu GW. 2005. Expression of 11 HOX genes is deregulated in esophageal squamous cell carcinoma. Clin Cancer Res 11:1044-1049.

Cook MB, Chow WH, and Devesa SS. 2009. Oesophageal cancer incidence in the United States by race, sex, and histologic type, 1977-2005. Br J Cancer 101:855-859. 10.1038/sj.bjc.6605246

Cui Y, Yan M, Zhang C, Xue J, Zhang Q, Ma S, Guan F, and Cao W. 2020. Comprehensive analysis of the HOXA gene family identifies HOXA13 as a novel oncogenic gene in kidney renal clear cell carcinoma. $J$ Cancer Res Clin Oncol 146:1993-2006. 10.1007/s00432-020-03259-x

Edgren G, Adami HO, Weiderpass E, and Nyren O. 2013. A global assessment of the oesophageal adenocarcinoma epidemic. Gut 62:1406-1414. 10.1136/gutjnl-2012-302412

Fitzgerald RC, di Pietro M, Ragunath K, Ang Y, Kang JY, Watson P, Trudgill N, Patel P, Kaye PV, Sanders S, O'Donovan M, Bird-Lieberman E, Bhandari P, Jankowski JA, Attwood S, Parsons SL, Loft D, Lagergren J, Moayyedi P, Lyratzopoulos G, de Caestecker J, and British Society of G. 2014. British Society of Gastroenterology guidelines on the diagnosis and management of Barrett's oesophagus. Gut 63:7-42. 10.1136/gutjnl-2013-305372

Global Burden of Disease Cancer C, Fitzmaurice C, Dicker D, Pain A, Hamavid H, Moradi-Lakeh M, MacIntyre MF, Allen C, Hansen G, Woodbrook R, Wolfe C, Hamadeh RR, Moore A, Werdecker A, Gessner BD, Te Ao B, McMahon B, Karimkhani C, Yu C, Cooke GS, Schwebel DC, Carpenter DO, Pereira DM, Nash D, Kazi DS, De Leo D, Plass D, Ukwaja KN, Thurston GD, Yun Jin K, Simard EP, Mills E, Park EK, Catala-Lopez F, deVeber G, Gotay C, Khan G, Hosgood HD, 3rd, Santos IS, Leasher JL, Singh J, Leigh J, Jonas JB, Sanabria J, Beardsley J, Jacobsen KH, Takahashi K, Franklin RC, Ronfani L, Montico M, Naldi L, Tonelli M, Geleijnse J, Petzold M, Shrime MG, Younis M, Yonemoto N, Breitborde N, Yip P, Pourmalek F, Lotufo PA, Esteghamati A, Hankey GJ, Ali R, Lunevicius R, Malekzadeh R, Dellavalle R, Weintraub R, Lucas R, Hay R, Rojas-Rueda D, Westerman R, Sepanlou SG, Nolte S, Patten S, Weichenthal S, Abera SF, Fereshtehnejad SM, Shiue I, Driscoll T, Vasankari T, Alsharif U, Rahimi-Movaghar V, Vlassov VV, Marcenes WS, Mekonnen W, Melaku YA, Yano Y, Artaman A, Campos I, MacLachlan J, Mueller U, Kim D, Trillini M, Eshrati B, Williams HC, Shibuya K, Dandona R, Murthy K, Cowie B, Amare AT, Antonio CA, CastanedaOrjuela C, van Gool CH, Violante F, Oh IH, Deribe K, Soreide K, Knibbs L, Kereselidze M, Green M, Cardenas R, Roy N, Tillmann T, Li Y, Krueger H, Monasta L, Dey S, Sheikhbahaei S, Hafezi-Nejad N, Kumar GA, Sreeramareddy CT, Dandona L, Wang H, Vollset SE, Mokdad A, Salomon JA, Lozano R, Vos T, Forouzanfar M, Lopez A, Murray C, and Naghavi M. 2015. The Global Burden of Cancer 2013. JAMA Oncol 1:505-527. 10.1001/jamaoncol.2015.0735

Goldman M, Craft B, Swatloski T, Cline M, Morozova O, Diekhans M, Haussler D, and Zhu J. 2015. The UCSC Cancer Genomics Browser: update 2015. Nucleic Acids Res 43:D812-817. 10.1093/nar/gku1073

Guo Q, Wang HB, Li YH, Li HF, Li TT, Zhang WX, Xiang SS, and Sun ZQ. 2016. Correlations of Promoter 
391

392

393

394

395

396

397

398

399

400

401

402

403

404

405

406

407

408

409

410

411

412

413

414

415

416

417

418

419

420

421

422

423

424

Methylation in WIF-1, RASSF1A, and CDH13 Genes with the Risk and Prognosis of Esophageal Cancer. Med Sci Monit 22:2816-2824. 10.12659/msm.896877

Hao X, Luo H, Krawczyk M, Wei W, Wang W, Wang J, Flagg K, Hou J, Zhang H, Yi S, Jafari M, Lin D, Chung C, Caughey BA, Li G, Dhar D, Shi W, Zheng L, Hou R, Zhu J, Zhao L, Fu X, Zhang E, Zhang C, Zhu JK, Karin M, Xu RH, and Zhang K. 2017. DNA methylation markers for diagnosis and prognosis of common cancers. Proc Natl Acad Sci U S A 114:7414-7419. 10.1073/pnas.1703577114

Kananen L, Marttila S, Nevalainen T, Jylhävä J, Mononen N, Kähönen M, Raitakari OT, Lehtimäki T, and Hurme M. 2016. Aging-associated DNA methylation changes in middle-aged individuals: the Young Finns study. BMC Genomics 17:103. 10.1186/s12864-016-2421-z

Kastner P, and Chan S. 2011. Role of Ikaros in T-cell acute lymphoblastic leukemia. World J Biol Chem 2:108-114. 10.4331/wjbc.v2.i6.108

Kaz A, Wong C, Luo Y, Virgin J, Washington M, Willis J, Leidner R, Chak A, and Grady W. 2011. DNA methylation profiling in Barrett's esophagus and esophageal adenocarcinoma reveals unique methylation signatures and molecular subclasses. Epigenetics 6:1403-1412. 10.4161/epi.6.12.18199

Kaz AM, Wong CJ, Varadan V, Willis JE, Chak A, and Grady WM. 2016. Global DNA methylation patterns in Barrett's esophagus, dysplastic Barrett's, and esophageal adenocarcinoma are associated with BMI, gender, and tobacco use. Clin Epigenetics 8:111. 10.1186/s13148-016-0273-7

Koch A, Joosten SC, Feng Z, de Ruijter TC, Draht MX, Melotte V, Smits KM, Veeck J, Herman JG, Van Neste L, Van Criekinge W, de Meyer T, and van Engeland M. 2018. Author Correction: Analysis of DNA methylation in cancer: location revisited. Nat Rev Clin Oncol 15:467. 10.1038/s41571-018-0028-9

Krause L, Nones K, Loffler KA, Nancarrow D, Oey H, Tang YH, Wayte NJ, Patch AM, Patel K, Brosda S, Manning S, Lampe G, Clouston A, Thomas J, Stoye J, Hussey DJ, Watson DI, Lord RV, Phillips WA, Gotley D, Smithers BM, Whiteman DC, Hayward NK, Grimmond SM, Waddell N, and Barbour AP. 2016. Identification of the CIMP-like subtype and aberrant methylation of members of the chromosomal segregation and spindle assembly pathways in esophageal adenocarcinoma. Carcinogenesis 37:356-365. 10.1093/carcin/bgw018

Lagergren J, Smyth E, Cunningham D, and Lagergren P. 2017. Oesophageal cancer. Lancet 390:2383-2396. $10.1016 / \mathrm{s} 0140-6736(17) 31462-9$

Laird PW. 2003. The power and the promise of DNA methylation markers. Nat Rev Cancer 3:253-266. $10.1038 / \mathrm{nrc} 1045$

Li J, Ye M, and Zhou C. 2020. Expression Profile and Prognostic Values of HOXA Family Members in Laryngeal Squamous Cell Cancer. Front Oncol 10:368. 10.3389/fonc.2020.00368

Lima SC, Hernández-Vargas H, Simão T, Durand G, Kruel CD, Le Calvez-Kelm F, Ribeiro Pinto LF, and Herceg Z. 2011. Identification of a DNA methylome signature of esophageal squamous cell carcinoma and potential 
425

426

427

428

429

430

431

432

433

434

435

436

437

438

439

440

441

442

443

444

445

446

447

448

449

450

451

452

453

454

455

456

457

458

epigenetic biomarkers. Epigenetics 6:1217-1227. 10.4161/epi.6.10.17199

Lin YS, Totsuka Y, He YT, Kikuchi S, Qiao YL, Ueda JK, Wei WQ, Inoue M, and Tanaka H. 2013. Epidemiology of Esophageal Cancer in Japan and China. Journal of Epidemiology 23:233-242. 10.2188/jea.JE20120162

Lordick F, Mariette C, Haustermans K, Obermannova R, Arnold D, and Committee EG. 2016. Oesophageal cancer: ESMO Clinical Practice Guidelines for diagnosis, treatment and follow-up. Ann Oncol 27:v50-v57. 10.1093/annonc/mdw329

Luebeck EG, Curtius K, Hazelton WD, Maden S, Yu M, Thota PN, Patil DT, Chak A, Willis JE, and Grady WM. 2017. Identification of a key role of widespread epigenetic drift in Barrett's esophagus and esophageal adenocarcinoma. Clin Epigenetics 9:113. 10.1186/s13148-017-0409-4

McBride DJ, Etemadmoghadam D, Cooke SL, Alsop K, George J, Butler A, Cho J, Galappaththige D, Greenman C, Howarth KD, Lau KW, Ng CK, Raine K, Teague J, Wedge DC, Cancer Study Group AO, Caubit X, Stratton MR, Brenton JD, Campbell PJ, Futreal PA, and Bowtell DD. 2012. Tandem duplication of chromosomal segments is common in ovarian and breast cancer genomes. J Pathol 227:446-455. 10.1002/path.4042

Mishra PP, Hänninen I, Raitoharju E, Marttila S, Mishra BH, Mononen N, Kähönen M, Hurme M, Raitakari O, Törönen P, Holm L, and Lehtimäki T. 2020. Epigenome-450K-wide methylation signatures of active cigarette smoking: The Young Finns Study. Biosci Rep 40. 10.1042/bsr20200596

Neumann LC, Weinhäusel A, Thomas S, Horsthemke B, Lohmann DR, and Zeschnigk M. 2011. EFS shows biallelic methylation in uveal melanoma with poor prognosis as well as tissue-specific methylation. $B M C$ Cancer 11:380. 10.1186/1471-2407-11-380

Oliveira VC, Lacerda MP, Moraes BBM, Gomes CP, Maricato JT, Souza OF, Schenkman S, Pesquero JB, Moretti NS, Rodrigues CA, and Popi AF. 2019. Deregulation of Ikaros expression in B-1 cells: New insights in the malignant transformation to chronic lymphocytic leukemia. J Leukoc Biol 106:581-594. 10.1002/jlb.Ma1118$454 \mathrm{r}$

Pech O, May A, Manner H, Behrens A, Pohl J, Weferling M, Hartmann U, Manner N, Huijsmans J, Gossner L, Rabenstein T, Vieth M, Stolte M, and Ell C. 2014. Long-term efficacy and safety of endoscopic resection for patients with mucosal adenocarcinoma of the esophagus. Gastroenterology 146:652-660.e651. 10.1053/j.gastro.2013.11.006

Peng DF, Razvi M, Chen H, Washington K, Roessner A, Schneider-Stock R, and El-Rifai W. 2009. DNA hypermethylation regulates the expression of members of the Mu-class glutathione S-transferases and glutathione peroxidases in Barrett's adenocarcinoma. Gut 58:5-15. 10.1136/gut.2007.146290

Robertson KD. 2005. DNA methylation and human disease. Nat Rev Genet 6:597-610. 10.1038/nrg1655

Robin X, Turck N, Hainard A, Tiberti N, Lisacek F, Sanchez JC, and Müller M. 2011. pROC: an open-source package for R and $\mathrm{S}+$ to analyze and compare ROC curves. BMC Bioinformatics 12:77. 10.1186/1471-2105$12-77$

PeerJ reviewing PDF | (2020:12:56122:1:1:NEW 16 Mar 2021) 
459

460

461

462

463

464

465

466

467

468

469

470

471

472

473

474

475

476

477

478

479

480

481

482

483

484

485

486

487

488

489

490

491

492

Schulmann K, Sterian A, Berki A, Yin J, Sato F, Xu Y, Olaru A, Wang S, Mori Y, Deacu E, Hamilton J, Kan T, Krasna MJ, Beer DG, Pepe MS, Abraham JM, Feng Z, Schmiegel W, Greenwald BD, and Meltzer SJ. 2005. Inactivation of p16, RUNX3, and HPP1 occurs early in Barrett's-associated neoplastic progression and predicts progression risk. Oncogene 24:4138-4148. 10.1038/sj.onc.1208598

Sertkaya S, Hamid SM, Dilsiz N, and Varisli L. 2015. Decreased expression of EFS is correlated with the advanced prostate cancer. Tumour Biol 36:799-805. 10.1007/s13277-014-2703-5

Si JG, Su YY, Han YH, and Chen RH. 2014. Role of RASSF1A promoter methylation in the pathogenesis of ovarian cancer: a meta-analysis. Genet Test Mol Biomarkers 18:394-402. 10.1089/gtmb.2014.0022

Siebring-van Olst E, Blijlevens M, de Menezes RX, van der Meulen-Muileman IH, Smit EF, and van Beusechem VW. 2017. A genome-wide siRNA screen for regulators of tumor suppressor p53 activity in human non-small cell lung cancer cells identifies components of the RNA splicing machinery as targets for anticancer treatment. Mol Oncol 11:534-551. 10.1002/1878-0261.12052

Smith E, De Young N, Pavey S, Hayward N, Nancarrow D, Whiteman D, Smithers B, Ruszkiewicz A, Clouston A, Gotley D, Devitt P, Jamieson G, and Drew P. 2008. Similarity of aberrant DNA methylation in Barrett's esophagus and esophageal adenocarcinoma. Molecular cancer 7:75. 10.1186/1476-4598-7-75

Smyth EC, Lagergren J, Fitzgerald RC, Lordick F, Shah MA, Lagergren P, and Cunningham D. 2017. Oesophageal cancer. Nat Rev Dis Primers 3:17048. 10.1038/nrdp.2017.48

Soutto M, Peng D, Razvi M, Ruemmele P, Hartmann A, Roessner A, Schneider-Stock R, and El-Rifai W. 2010. Epigenetic and genetic silencing of CHFR in esophageal adenocarcinomas. Cancer 116:4033-4042. $10.1002 /$ cncr. 25151

Tian Y, Morris TJ, Webster AP, Yang Z, Beck S, Feber A, and Teschendorff AE. 2017. ChAMP: updated methylation analysis pipeline for Illumina BeadChips. Bioinformatics 33:3982-3984. 10.1093/bioinformatics/btx 513

Vital AL, Tabernero MD, Castrillo A, Rebelo O, Tão H, Gomes F, Nieto AB, Resende Oliveira C, Lopes MC, and Orfao A. 2010. Gene expression profiles of human glioblastomas are associated with both tumor cytogenetics and histopathology. Neuro Oncol 12:991-1003. 10.1093/neuonc/noq050

Xu E, Gu J, Hawk E, Wang K, Lai M, Huang M, Ajani J, and Wu X. 2013a. Genome-wide methylation analysis shows similar patterns in Barrett's esophagus and esophageal adenocarcinoma. Carcinogenesis 34:2750-2756. 10.1093/carcin/bgt286

Xu E, Gu J, Hawk ET, Wang KK, Lai M, Huang M, Ajani J, and Wu X. 2013b. Genome-wide methylation analysis shows similar patterns in Barrett's esophagus and esophageal adenocarcinoma. Carcinogenesis 34:2750-2756. $10.1093 /$ carcin/bgt286

Xu XC. 2009. Risk factors and gene expression in esophageal cancer. Methods Mol Biol 471:335-360. 10.1007/978$1-59745-416-2 \_17$

PeerJ reviewing PDF | (2020:12:56122:1:1:NEW 16 Mar 2021) 
493 Yang JZ, Ji AF, Wang JS, Chen ZY, and Wen SW. 2014. Association between Ras association domain family 1A 494 promoter methylation and esophageal squamous cell carcinoma: a meta-analysis. Asian Pac J Cancer Prev $495 \quad 15: 3921-3925.10 .7314$ apjcp.2014.15.9.3921

496 Zeng H, Li H, Zhao Y, Chen L, and Ma X. 2019. Transcripto-based network analysis reveals a model of gene 497 activation in tongue squamous cell carcinomas. Head Neck 41:4098-4110. 10.1002/hed.25952

498 Zou H, Molina JR, Harrington JJ, Osborn NK, Klatt KK, Romero Y, Burgart LJ, and Ahlquist DA. 2005a. Aberrant 499 methylation of secreted frizzled-related protein genes in esophageal adenocarcinoma and Barrett's esophagus. $500 \quad$ Int $J$ Cancer 116:584-591. 10.1002/ijc.21045

501 Zou H, Osborn NK, Harrington JJ, Klatt KK, Molina JR, Burgart LJ, and Ahlquist DA. 2005b. Frequent methylation 502 of eyes absent 4 gene in Barrett's esophagus and esophageal adenocarcinoma. Cancer Epidemiol Biomarkers $503 \quad$ Prev 14:830-834. 10.1158/1055-9965.Epi-04-0506

504 
Figure 1

Workflow of the study.

Illustration of data process and analyses of this study. 
TCGA EAC methylation data

(89 tumours and 16 normal samples)

GSE72872

(125 EAC tumours and 64 normal samples)

TCGA EAC RNASeq data

68 EAC tumour and 5normal samples

TCGA ESCC methylation data

(96 ESCC tumour samples)

GSE69270

(184 normal blood samples)

Correlation analysis

841 hypermethylated DMPs

834 hypermethylated DMPs

LASSO bionomial logistic regression

GSE81334

(23 EAC tumour and 56 normal samples)

GSE104707

(24 EAC tumour and 52 normal samples)

4 EAC diagnostic

hypermethylated CpGs

GSE89181

(24 EAC tumour and 11 normal samples) 


\section{Figure 2}

Differentially methylated CpG sites using TCGA EAC and GSE72872 datasets.

(A-C) The volcano map of DMPs between (A) TCGA stage I/II EAC, (B) TCGA stage III/IV EAC, (C) EAC in GSE72872 vs. the normal samples. ( $D$ and E) The Venn diagrams. The data show the coincidence of 4852 hypermethylated DMPs (D) and 540 hypomethylated DMPs (E) in TCGA EAC and GSE72872 datasets.

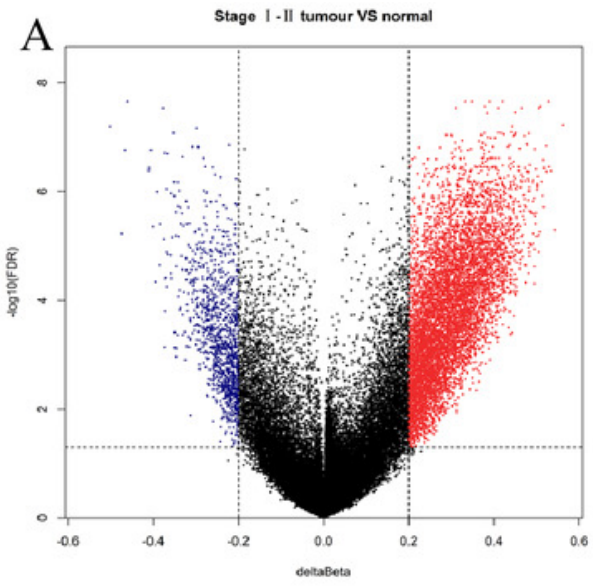

$\mathrm{D}$

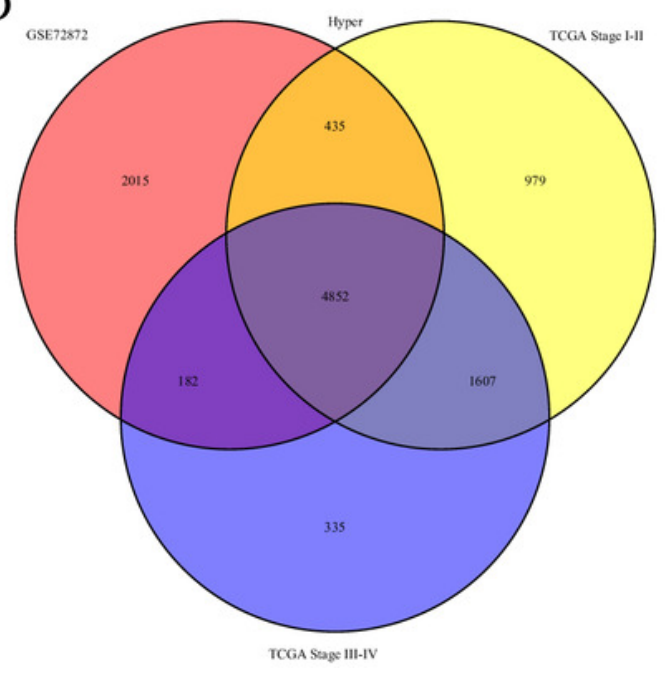

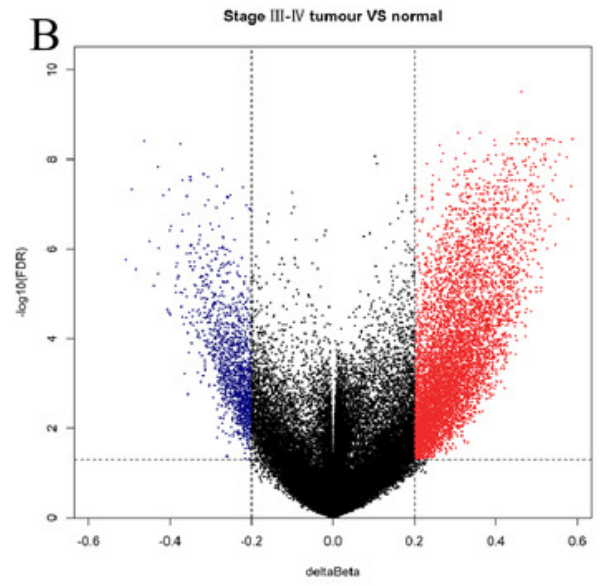

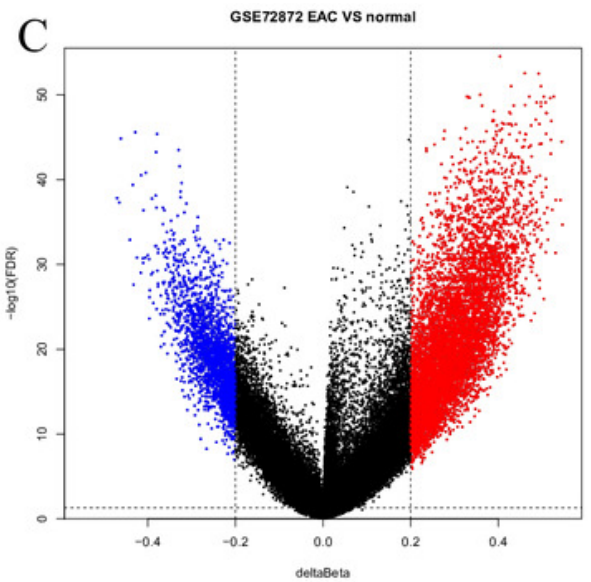

$\mathrm{E}$

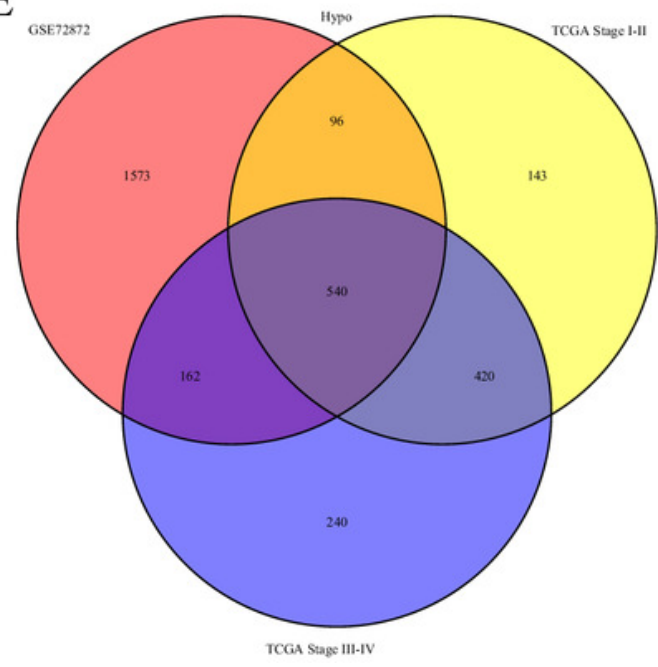




\section{Figure 3}

Distribution of differentially methylated positions (DMPs).

(A) Distribution of the 5392 DMPs in different chromosomes. (B) Distribution of the 5392 DMPs in the $1500 \mathrm{bp}$ and/or $200 \mathrm{bp}$ upstream of the transcription starting sites (TSS1500 and/or TSS200). (C) Distribution of the 5392 DMPs in terms of CpG features.

A

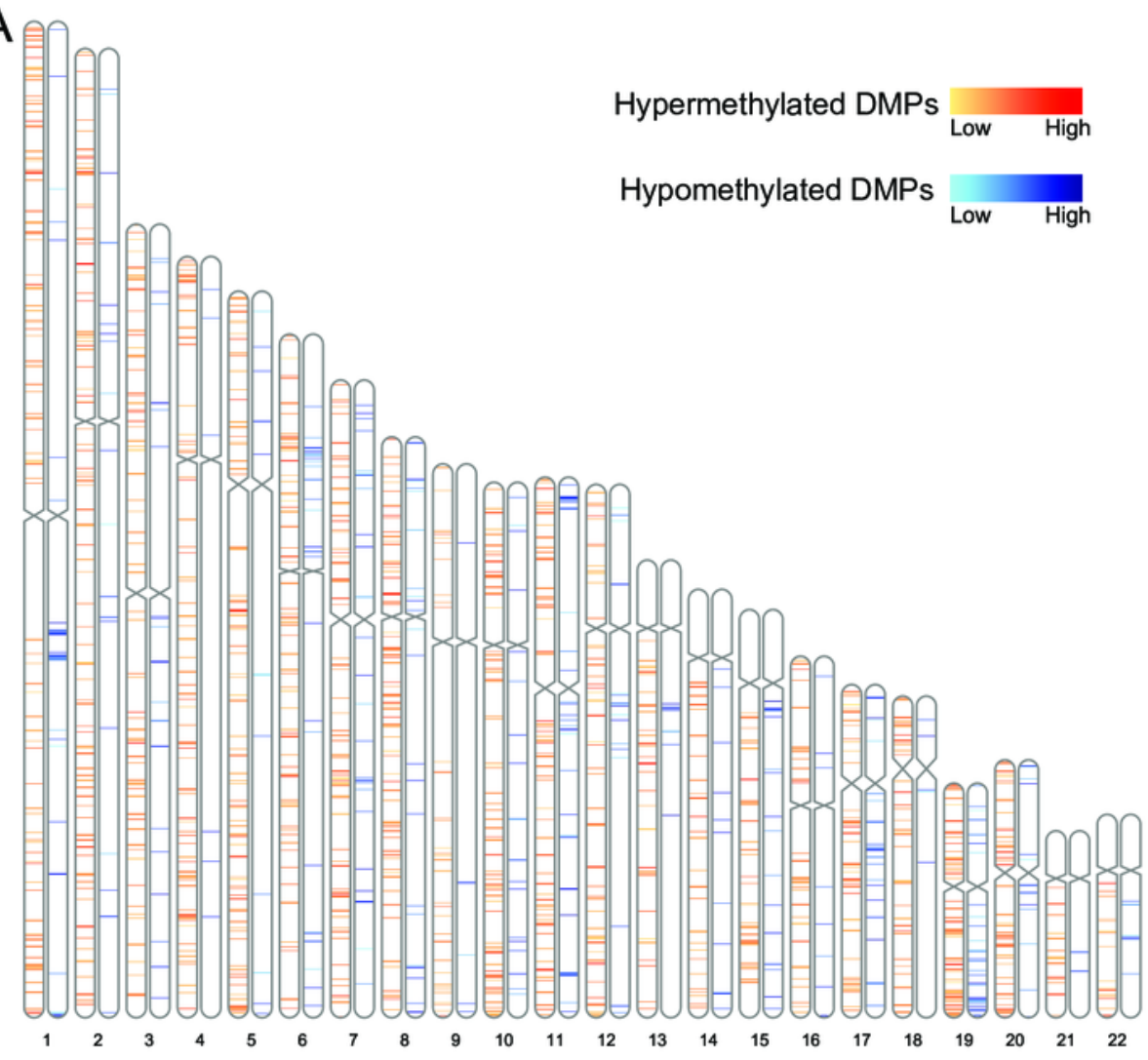

B

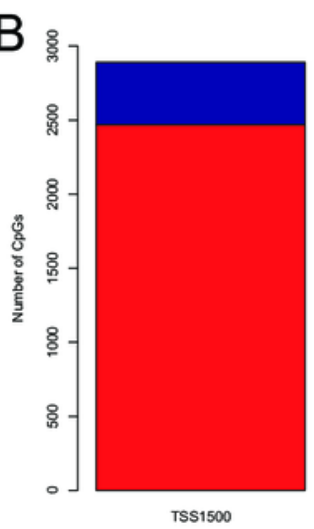

C

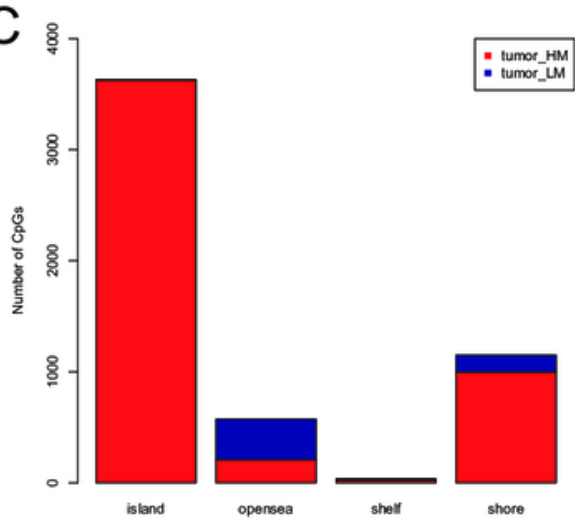




\section{Figure 4}

Heatmap of differentially methylated CpGs and expression of corresponding genes.

(A) Heatmap of methylation levels of the 898 differentially methylated positions. (B) Heatmap of expression of the 363 differentially methylated genes. HM_gene, hypermethylated gene, LM_gene, hypomethylated gene.
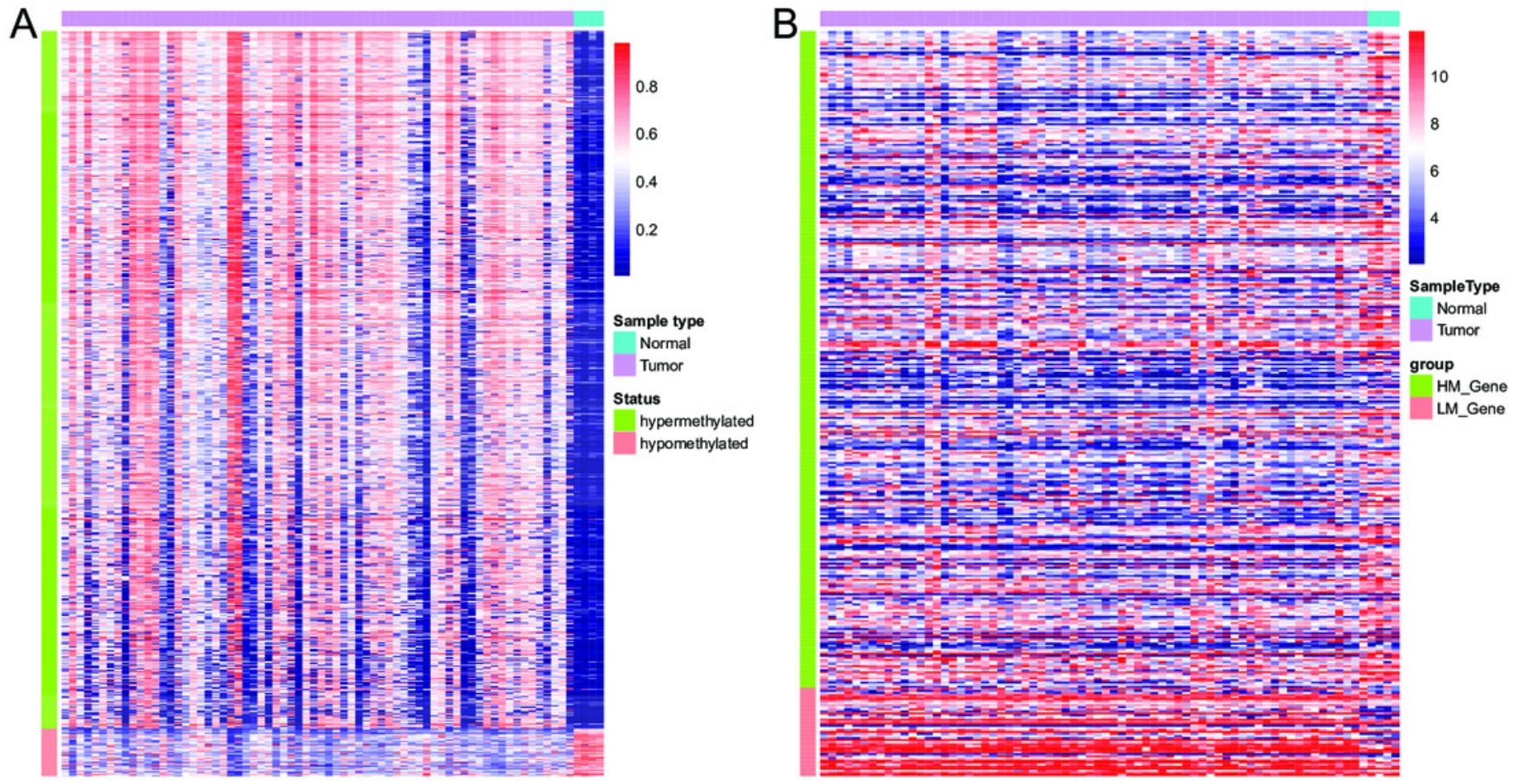


\section{Figure 5}

Screening of candidate EAC-specific diagnostic biomarkers.

(A) Heatmap of methylation levels of the 649 EAC hypermethylated CpGs among the blood, different EAC and normal samples. (B) The risk score. The score was calculated using the diagnostic model of each ESSC and different EAC datasets. (C) Heatmap of the average methylation levels of four candidate CpGs in EAC and other cancer types. ACC_T, Adrenocortical carcinoma; BLCA_T, Bladder Urothelial carcinoma; BRCA_T, Breast invasive carcinoma; CESC_T, Cervical squamous cell carcinoma and endocervical adenocarcinoma; CHOL_T, Cholangiocarcinoma; COAD_T, Colon adenocarcinoma; DLBC_T, Diffuse Large B-cell Lymphoma; GBM_T, Glioblastoma multiforme; HNSC_T, Head and Neck squamous cell carcinoma; KICH_T, Kidney Chromophobe; KIRC_T, Kidney renal clear cell carcinoma; KIRP_T, Kidney renal papillary cell carcinoma; LAML_T, Acute Myeloid Leukemia; LGG_T, Brain Lower Grade Glioma; LIHC_T, Liver hepatocellular carcinoma; LUAD_T, Lung adenocarcinoma; LUSC_T, Lung squamous cell carcinoma; MESO_T, Mesothlioma, OV_T, Ovarian serous cystadenocarcinoma; PAAD_T, Pancreatic adenocarcinoma; PCPG_T, Pheochromocytoma and Paraganglioma; PRAD_T, Prostate adenocarcinoma; READ_T, Rectum adenocarcinoma; STAD_T, stomach adenocarcinoma; UCEC_T, Uterine Corpus Endometrial Carcinoma. 

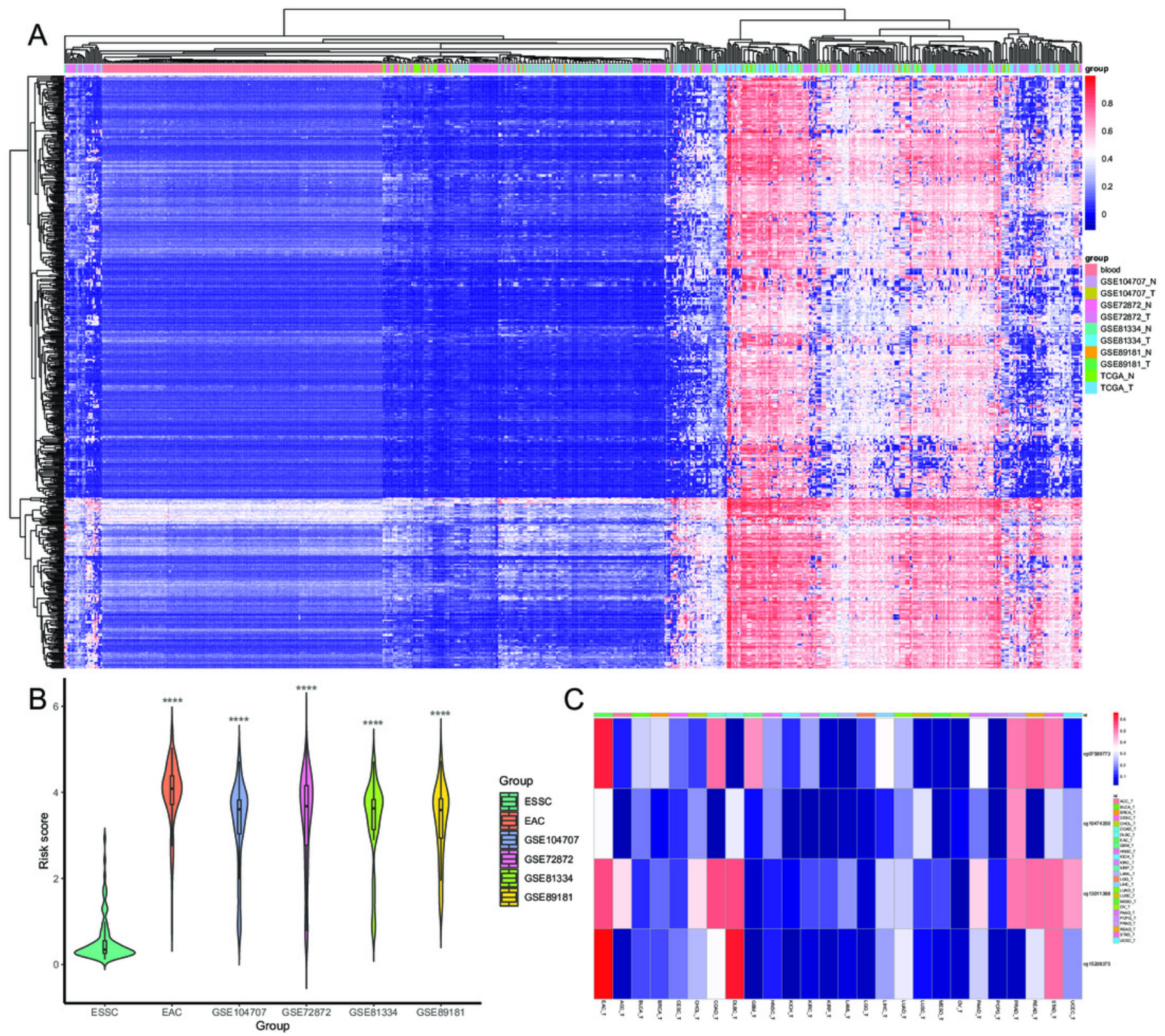
Figure 6

Methylation levels of these four CpGs between EAC and normal samples in other EAC datasets.

Four CpGs methylation levels between EAC and normal samples in GSE72872 (A), GSE81334 (B), GSE89181 (C), and GSE104707 (D).
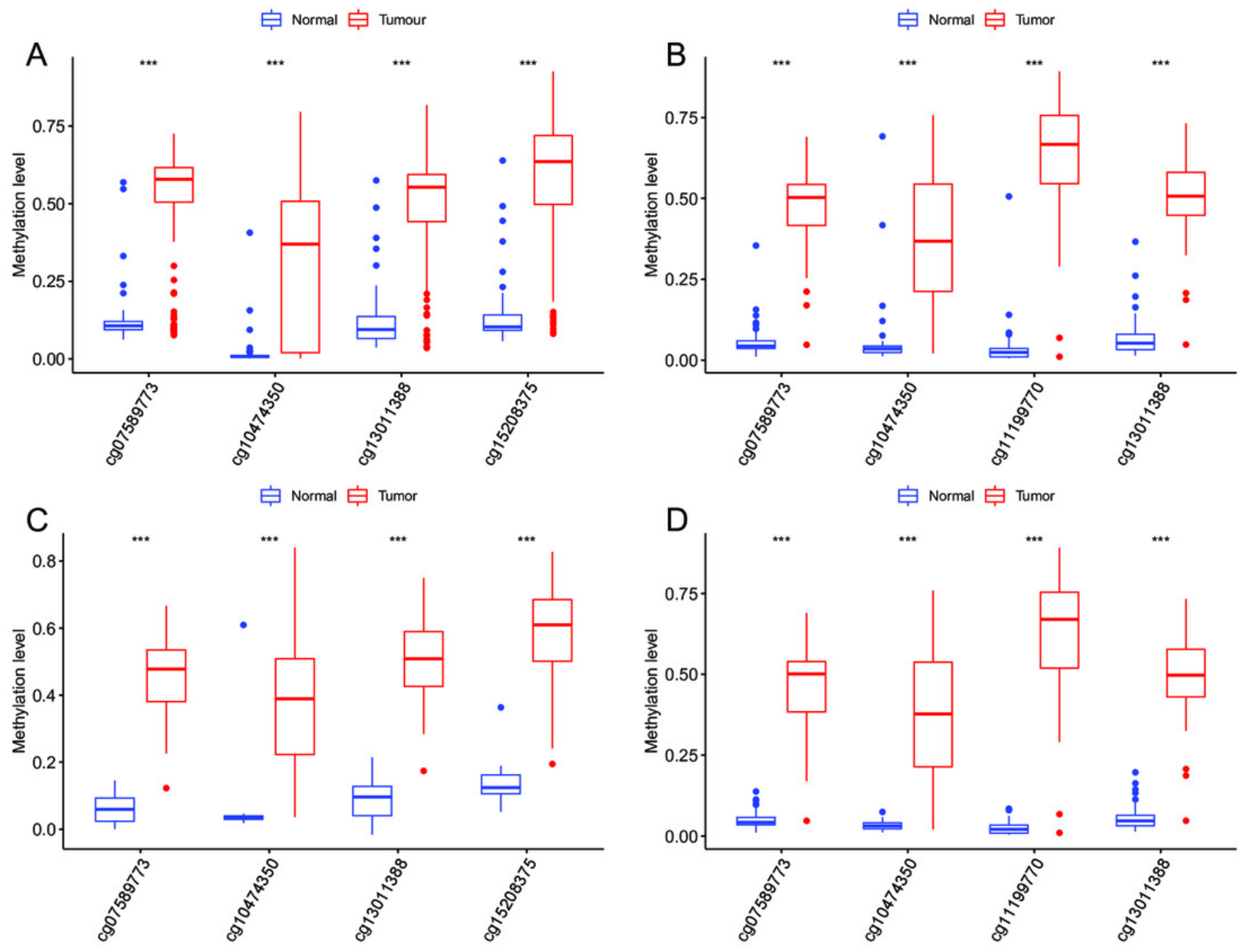
Figure 7

Methylation levels of all CpGs at the promoter regions of these four corresponding genes.

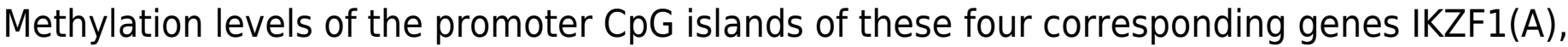
HOXA7(B), EFS(C), and TSHZ3 (D) between EAC and normal samples in TCGA. *p < 0.05; **p $<0.01$, and $* * p<0.001$.
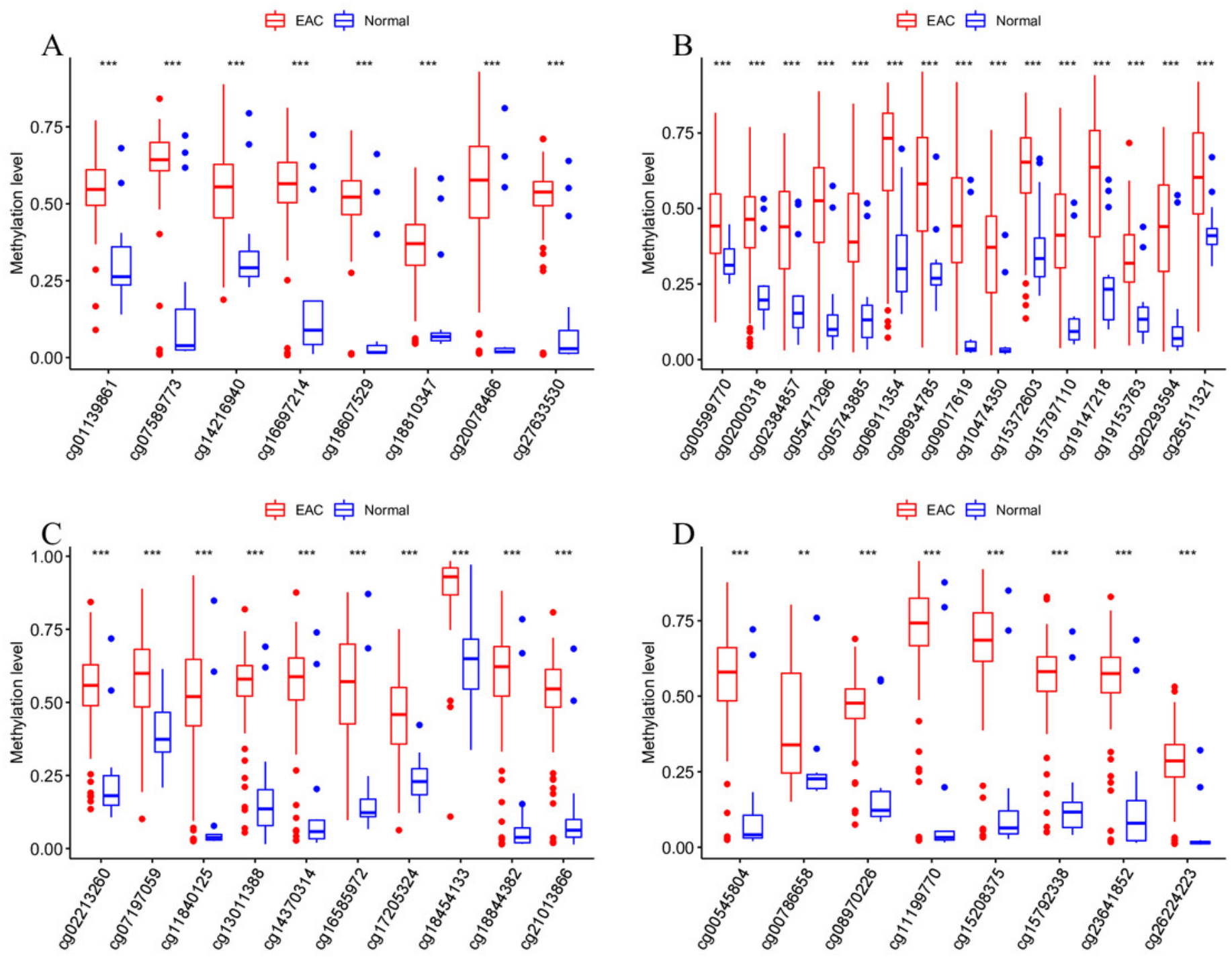
Figure 8

Evaluation power of this diagnostic model.

The risk score was calculated by using data of the model of EAC and normal samples in TCGA (A), GSE81334 (B), GSE89181 (C), and GSE104707 (D).
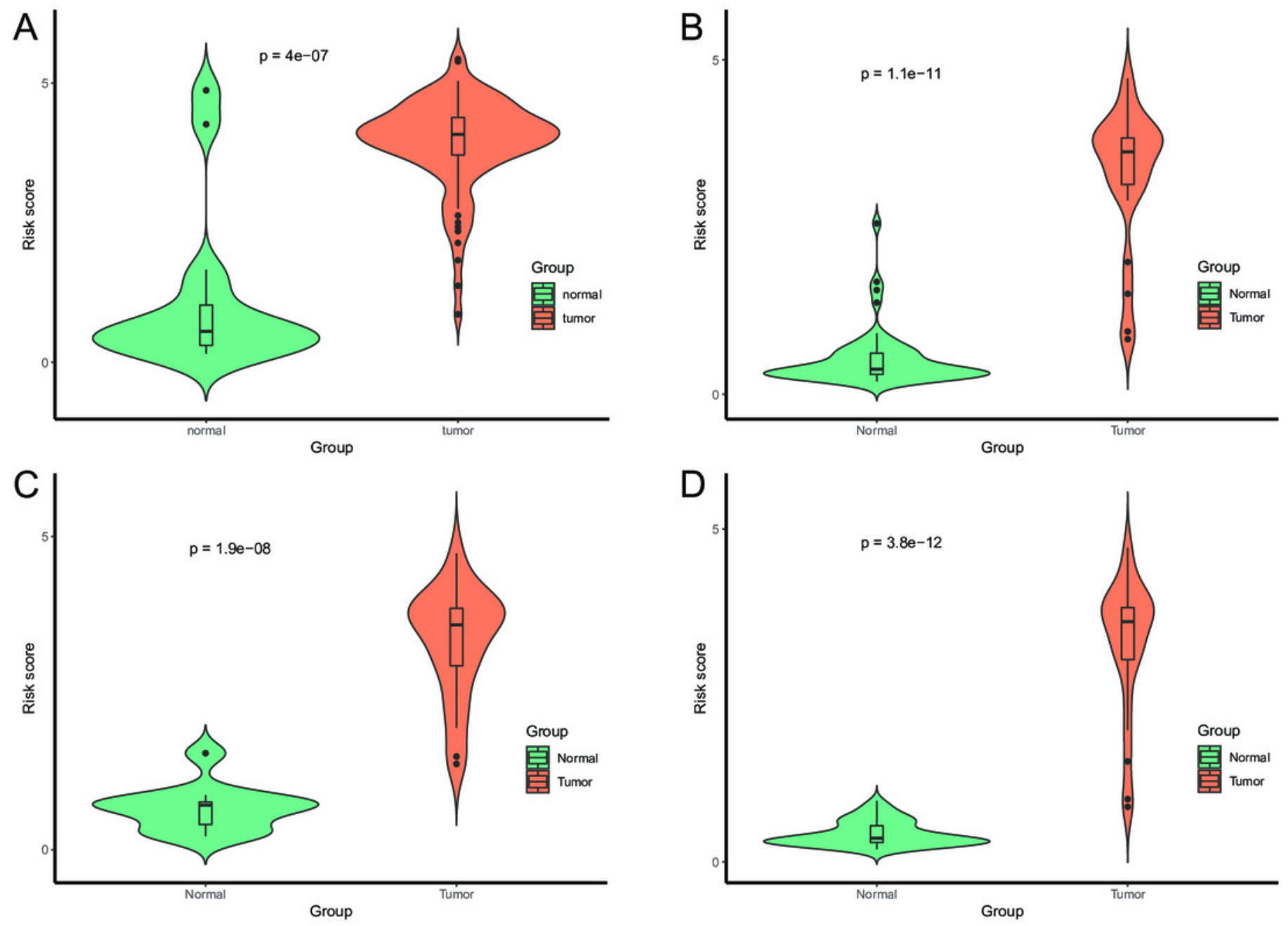
Figure 9

Evaluation power of this diagnostic model.

The ROC curves of this diagnostic model in TCGA (A), GSE81334 (B), GSE89181 (C), and GSE104707 (D).
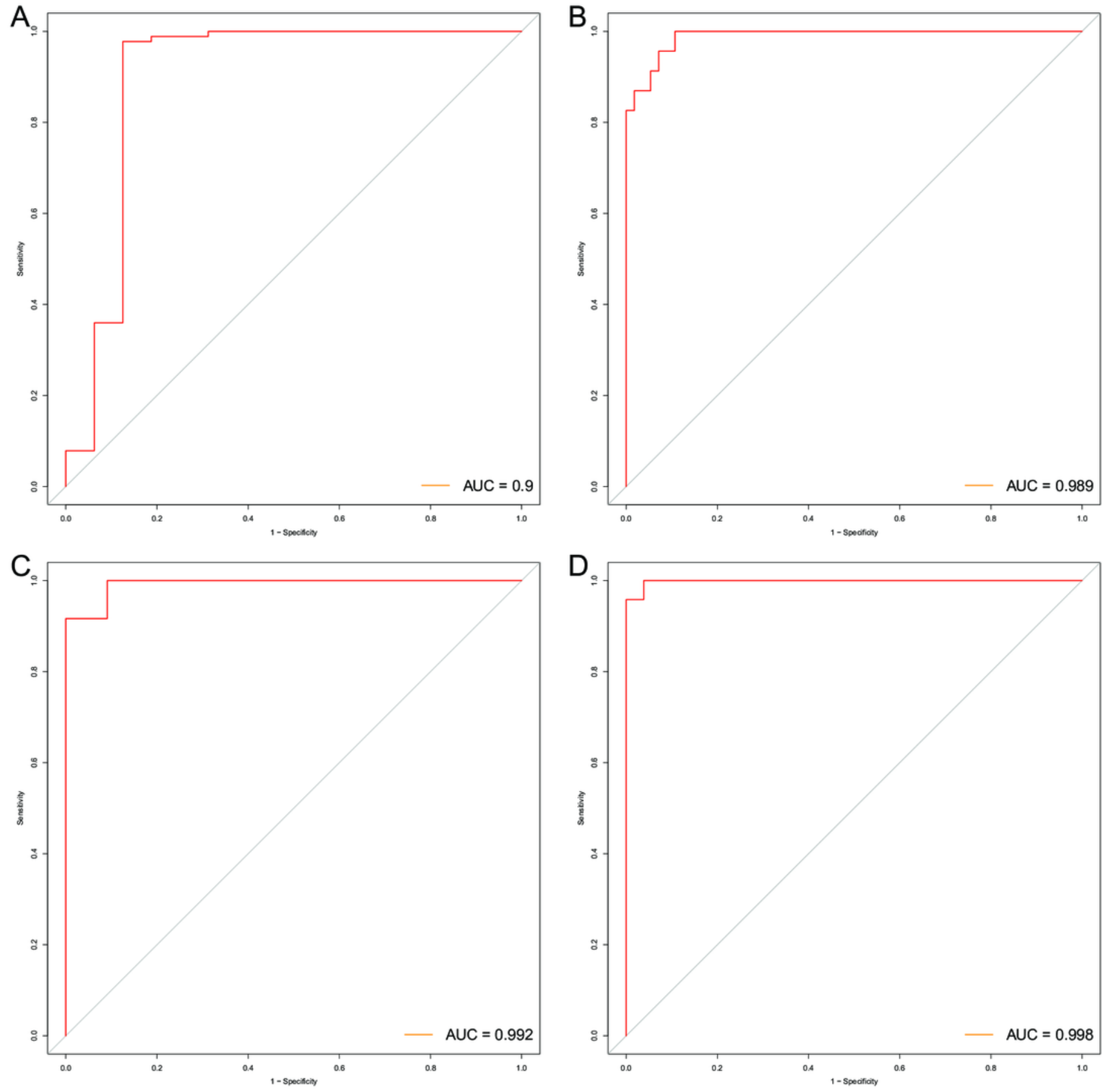
Figure 10

Evaluation diagnostic performance of this model in diagnosis of early stage EAC.

( $A$ and $C$ ) The risk score of this model in stage I EAC and normal samples in TCGA (A) and GSE89181 (C). (B and D) The ROC curves of this model in stage I EAC and normal samples in TCGA (B) and GSE89181(D).
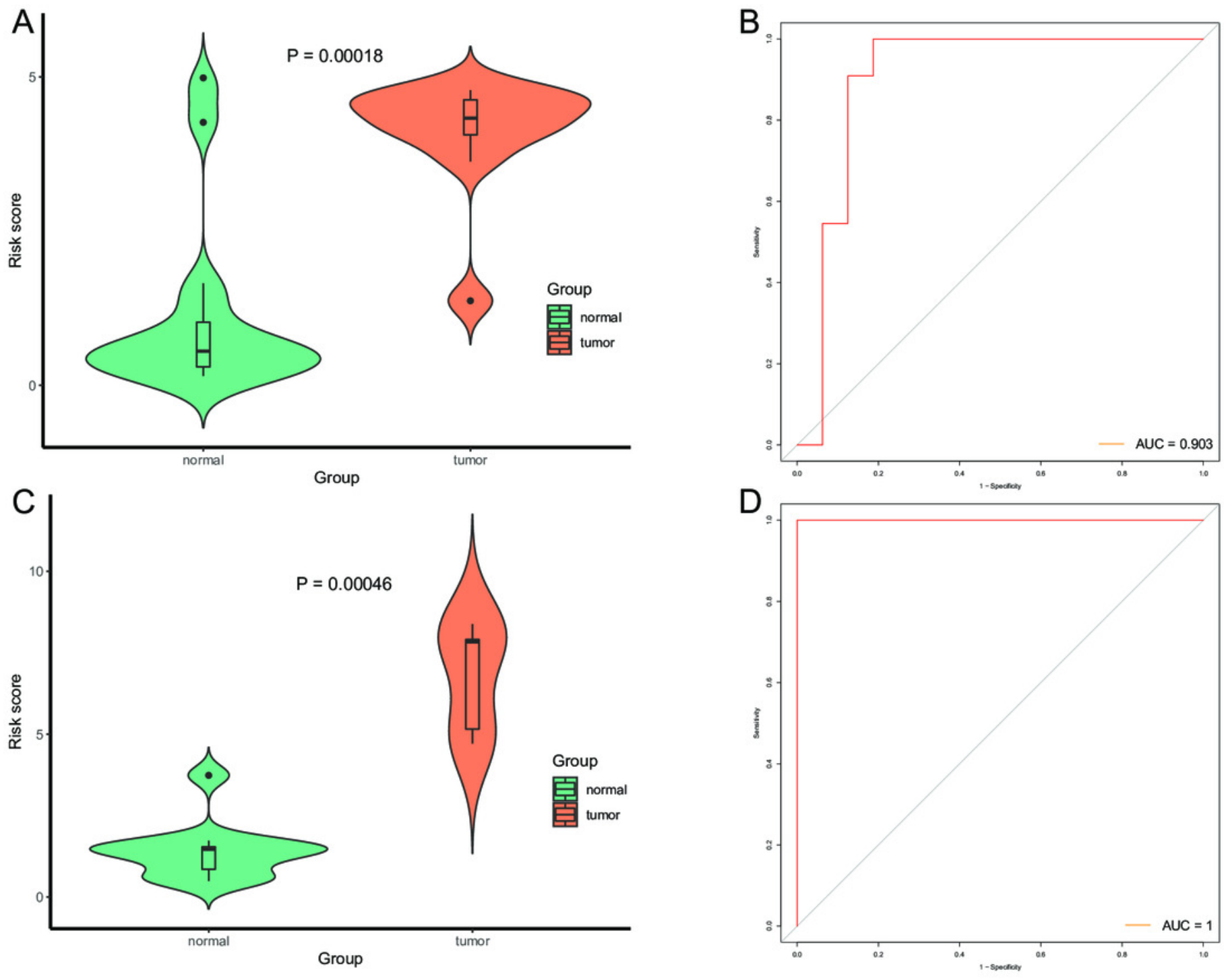
Table $\mathbf{1}$ (on next page)

Information of the four candidate $\mathrm{CpGs}$

Information of the four candidate CpGs 
Manuscript to be reviewed

\begin{tabular}{ccccccc}
\hline CpG & $\begin{array}{c}\text { Chromosom } \\
\mathrm{e}\end{array}$ & Gene & Feature & Start & End & Coefficient \\
\hline $\begin{array}{c}\operatorname{cg} 0758977 \\
3\end{array}$ & chr7 & IKZF1 & $\begin{array}{c}\text { TSS1500- } \\
\text { island }\end{array}$ & 50304287 & 50304288 & 2.186 \\
$\operatorname{cg} 1047435$ & chr7 & $\begin{array}{c}\text { HOXA } \\
7\end{array}$ & $\begin{array}{c}\text { TSS1500- } \\
\text { island }\end{array}$ & 27156936 & 27156937 & 0.504 \\
$\operatorname{cg} 1301138$ & chr14 & EFS & TSS200-island & 23365700 & 23365701 & 1.55 \\
8 & chr19 & TSHZ3 & $\begin{array}{c}\text { TSS1500- } \\
\text { island }\end{array}$ & 31350649 & 31350650 & 2.371 \\
\hline
\end{tabular}

Information of the four candidate CpGs 